\title{
Hesperetin inhibits the maturation and function of monocyte- derived dendritic cells from patients with asthma
}

\author{
XIAOYAN GU ${ }^{1}$, LINFU ZHOU ${ }^{2}$, QIANG DU ${ }^{2}$, DESHENG JIANG $^{1}$, XIAOFAN YANG ${ }^{3}$, \\ $\mathrm{XIAOHUI} \mathrm{JI}^{3}$ and KAISHENG YIN ${ }^{2}$ \\ ${ }^{1}$ Department of Respiratory Medicine, The 454th Hospital of Chinese PLA, Nanjing 210002; \\ ${ }^{2}$ Department of Respiratory Medicine, The First Affiliated Hospital, and ${ }^{3}$ Department of Microbiology and \\ Immunology, Nanjing Medical University, Nanjing 210029, P.R. China
}

Received December 19, 2008; Accepted March 6, 2009

DOI: $10.3892 / \mathrm{mmr}+00000129$

\begin{abstract}
Dendritic cells (DCs) are crucial regulators of allergic diseases. Hesperetin, an important bioactive compound in Chinese traditional medicine, has antioxidant and antiallergic properties. In this study, we examined whether hesperetin influences surface molecule expression, cytokine production, the capacity to induce $\mathrm{T}$ cell proliferation, and the underlying signaling pathway in monocyte-derived DCs from patients with allergic asthma. The results show that hesperetin significantly suppressed Der p 1-induced HLA-DR, CD86 and CD83 expression in DCs. However, the secretion of IL-10 was not affected. Hesperetin-treated DCs exhibited a reduced ability to stimulate autologous $\mathrm{CD} 4^{+} \mathrm{T}$ cells, accompanied by less Th2 polarization. In addition, the Der $\mathrm{p} 1$-induced phosphorylation of $\mathrm{I} \kappa \mathrm{B} \alpha$ and the translocation of NF- $\kappa \mathrm{B}$ p 65 were inhibited in the presence of hesperetin. These novel findings provide insight into the immunopharmacological role of hesperetin in DC-based allergic diseases.
\end{abstract}

\section{Introduction}

Asthma is an allergic disorder characterized by Th2-mediated eosinophilic airway inflammation, airway hyperresponsiveness and airway remodeling (1). Dendritic cells (DCs) are professional antigen-presenting cells that have the ability to stimulate naive $\mathrm{T}$ cells and to initiate the differentiation of $\mathrm{CD} 4^{+} \mathrm{T}$ cells into Th1 or Th2 subsets (2). There are reports which suggest that in vivo DCs play a crucial role in the establishment of the allergic inflammatory reaction: their numbers increase in the lungs of asthmatic patients (3); bronchial epithelial DCs issued from asthmatic patients activate $\mathrm{CD} 4^{+} \mathrm{T}$ cells with a preferential secretion of Th2 cytokines such as IL-4 and IL-5

Correspondence to: Dr Kai-Sheng Yin, Department of Respiratory Medicine, The First Affiliated Hospital, Nanjing Medical University, 300 Guangzhou Road, Nanjing 210029, P.R. China

E-mail: yinks@126.com

Key words: monocytes, dendritic cells, asthma, hesperetin
(4); selective DC depletion in ovalbumin-sensitized mice leads to a decrease in immunoglobulin ( $\mathrm{Ig}) \mathrm{E}$ production, the abolition of Th2 response and a lack of eosinophil recruitment (5). DCs are therefore becoming a viable drug target in allergic asthma due to their crucial role in the initiation of immune response. Steroids and immunosuppressants have been used to treat allergic diseases (6), but have failed to effect significant improvements. Traditional herbal medicines have been developed for allergic diseases, and have received increasing attention due to their effectiveness (7).

Hesperetin (5,7,3'trihydroxyl-4'-methoxyl-flavanone) is a bioactive compound that belongs to a class of flavonoids called flavanones, which are abundant in citrus fruits. The compound is used in Chinese traditional medicine and is known to possess several biological and pharmacological activities, including antioxidant (8), anti-inflammatory (9), and anticarcinogenic properties (10). It is also specifically known to alter signal transduction pathways (11). Recently, hesperetin was reported to exhibit an anti-allergic action by inhibiting histamine release from RBL-2H3 cells $(12,13)$. However, the cellular targets of hesperetin in the immune system have yet to be studied.

In this study, we aimed to investigate the effect of a noncytotoxic concentration of hesperetin on the maturation and function of monocyte-derived DCs from patients with allergic asthma. Our results indicate that hesperetin is a potent inhibitor of DCs. These findings provide new insight into the immunopharmacology of hesperetin.

\section{Materials and methods}

Reagents. Hesperetin was obtained from Sigma Chemical Co. (St. Louis, MO, USA) and dissolved in DMSO (0.1\%). The recombinant human (rh) granulocyte macrophage-colonystimulating factor (GM-CSF) rhIL-4 was purchased from Peprotech (London, UK).

Subjects. Ten non-smoking patients with allergic asthma (6 females and 4 males) were recruited from the database of the China Asthma Alliance Jiangsu Branch according to the Global Initiative for Asthma (GINA) 2006 guidelines (14). All allergic patients presented positive skin prick tests for the 
house dust mite Dermatophagoides pteronyssinus, as well as elevated total serum IgE concentrations $(206.6 \pm 30.8 \mathrm{IU} / \mathrm{ml})$. None of the subjects had respiratory infections and none had used corticosteroids in the previous 4 weeks. Short-acting $\beta_{2^{-}}$ agonists alone were inhaled on demand as rescue medication, but were discontinued $12 \mathrm{~h}$ prior to blood sampling. All subjects gave their written informed consent. The study was approved by the Jiangsu Province Hospital Ethics Committee.

Generation of monocyte-derived dendritic cells. DCs were generated from lymphocyte-depleted peripheral blood mononuclear cells (PBMCs) according to established procedure (15). Briefly, PBMCs were separated on Ficoll (Haoyang Biotech, Tianjing, China) from samples of heparinized venous blood obtained from patients. Monocytes were derived from PBMCs depleted of NK, B and T cells with anti-CD16, anti-CD19 and anti-CD3, as well as with goat anti-mouse Ig-conjugated magnetic beads (Miltenyi Biotech, USA). The cells were then cultured $\left(2 \times 10^{6}\right.$ cells/well $)$ in 6 -well flatbottomed culture plates (Coster, Cambridge, MA, USA) in RPMI-1640 supplemented with $1 \%$ antibiotics and $10 \%$ fetal calf serum (Gibco, Grand Island, NY) for 7 days in the presence of $1000 \mathrm{U} / \mathrm{ml} \mathrm{GM-CSF}$ and $500 \mathrm{U} / \mathrm{ml} \mathrm{IL-4.} \mathrm{Every}$ other day, half of the medium in the cell cultures was replaced with fresh medium.

Stimulation of dendritic cells. On day 7, immature DCs (iDCs) were harvested. To explore the effects of hesperetin on DC maturation, iDCs $\left(1 \times 10^{6}\right.$ cells $\left./ \mathrm{ml}\right)$ were pulsed with medium alone or with predetermined non-cytotoxic doses of house dust mite allergen (100 ng/ml Der p 1) (ALKScherax, Hamburg, Germany) in the presence or absence of hesperetin $(12.5,25$ and $50 \mu \mathrm{M}$ ). Supernatants were collected after a 24-h culture. After extensive washing, cells were coincubated with $\mathrm{T}$ cells or subjected to other analyses.

MTT assay. Cell viability was determined using the MTT assay in 96-well plates as previously described (16). The cells ( $2 \times 10^{4}$ cells/96 well) were treated with various concentrations of hesperetin for $24 \mathrm{~h}$, then incubated with MTT (Sigma Chemical Co.) for $4 \mathrm{~h}$ at $37^{\circ} \mathrm{C}$. After the removal of unconverted MTT, $100 \mu \mathrm{l}$ of isopropanol (in $0.04 \mathrm{~N}$ hydrochloric acid) was added to dissolve the formazan crystals. Absorbance was read at $570 \mathrm{~nm}$ using the CliniBio-128C spectrophotometer (Austria). Cell viability was calculated as the relative absorbance compared to the control.

Flow cytometry. On day 8, the DCs were collected, washed and incubated for $30 \mathrm{~min}$ at $4^{\circ} \mathrm{C}$ with the following fluorescentlabeled mouse anti-human monoclonal antibodies (mAbs): fluorescein isothiocyanate (FITC)-conjugated anti-CD80, anti-CD83 or anti-CD1a; Phycoerythrin (PE)-conjugated antiCD86, anti-HLA-DR or anti-CD14 (eBioscience, San Diego, CA). After washing, the cells were fixed in $1 \%$ paraformaldehyde and analyzed using a FACSCalibur (BectonDickinson).

Proliferation assay. Autologous $\mathrm{T}$ cells were isolated and enriched using RosettSep CD4 reagent (StemCell Technologies) as previously described (17). DCs and T cells were

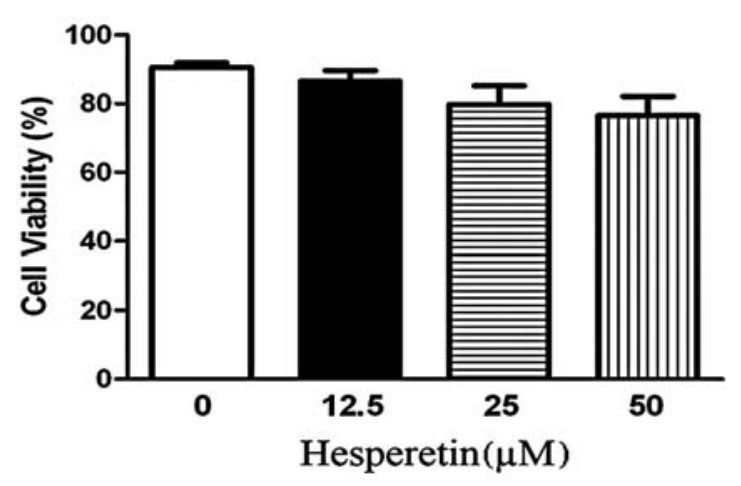

Figure 1. Effects of hesperetin on the viability of dendritic cells (DCs). Immature DCs were treated with various concentrations of hesperetin for $24 \mathrm{~h}$. Cell viability was determined using the MTT assay, and was represented by the relative absorbance compared to the control. Data are presented as the means $\pm \operatorname{SEM}(\mathrm{n}=10)$

used as stimulators and responders, respectively. Stimulators were co-cultured with responders $\left(2 \times 10^{5} /\right.$ well $)$ in triplicate at serial ratios $(1: 100,1: 50,1: 20$ and 1:10) in 96-well plates (200 $\mu \mathrm{l} /$ well) in $5 \% \mathrm{CO}_{2}$ at $37^{\circ} \mathrm{C}$ for $96 \mathrm{~h}$, then pulsed with $0.5 \mu \mathrm{Ci} /$ well of $\left[{ }^{3} \mathrm{H}\right]$ thymidine for the final $16 \mathrm{~h}$ before liquid scintillography. The counts per min (cpm) of triplicate wells were calculated.

Dendritic cell-T-cell cocultures. Various treated DCs were coincubated with autologous $\mathrm{CD} 4^{+} \mathrm{T}$ cells at a ratio of 1:10 for $48 \mathrm{~h}$. The supernatants were harvested and assayed for IL-4 and IFN- $\gamma$ production.

Cytokine assay. Cellular supernatants were harvested on day 8 to measure the levels of IL-10 and IL-12 p70 by enzyme-linked immunosorbent assay (ELISA, Biosource, USA). IL-4 and IFN- $\gamma$ by $\mathrm{T}$ cells cocultured with DCs was measured in the supernatants by ELISA according to the manufacturer's protocols.

Western blot analysis. On day 7, iDCs were recovered and pretreated with $50 \mu \mathrm{M}$ hesperetin for $40 \mathrm{~min}$, and then exposed to $100 \mathrm{ng} / \mathrm{ml}$ Der p 1 for $60 \mathrm{~min}$ at $37^{\circ} \mathrm{C}$. Cells were washed twice in ice-cold PBS, and cytoplasmic and nuclear proteins were extracted (15). Denatured proteins ( $80 \mu \mathrm{g})$ were separated on $10-12 \%$ SDS-PAGE and blotted onto polyvinylidene difluoride membranes. The membranes were probed with either rabbit anti-human p65, mouse anti-human $\mathrm{I} \kappa \mathrm{B} \alpha$, mouse antihuman phospho-IкB $\alpha(\mathrm{pI} \kappa \mathrm{B} \alpha, \mathrm{Ser} 32 / 36)$ or mouse anti-human $ß$-actin antibody (Cell Signaling Technology, Beverly, MA; all at a 1:1000 dilution) overnight at $4{ }^{\circ} \mathrm{C}$, and then incubated with a horseradish peroxidase-conjugated secondary antibody (Cell Signaling Technology). The immunoblots were visualized with an enhanced chemiluminescence detection system (Pierce, Rockford, IL).

Statistics. Data are expressed as the means \pm SEM of the indicated number of experiments. Statistical significance was estimated using the Student's t-test for unpaired observations, and one-way analysis of variance for the comparison of differences. $\mathrm{P}<0.05$ was considered significant. 
Table I. Expression of CD80, CD86, CD83 and HLA-DR on dendritic cells.

\begin{tabular}{lllll}
\hline & CD80 (\%) & CD86 (\%) & CD83 (\%) & HLA-DR (\%) \\
\hline iDCs & & & & \\
$\quad$ Medium & $25.69 \pm 4.30$ & $37.18 \pm 3.96$ & $10.99 \pm 2.70$ & $32.15 \pm 4.62$ \\
Der p 1 & $42.82 \pm 6.85$ & $63.61 \pm 6.71^{\mathrm{a}}$ & $45.18 \pm 2.87^{\mathrm{a}}$ & $55.48 \pm 8.03^{\mathrm{a}}$ \\
Der p 1+ H & $38.00 \pm 3.42$ & $41.28 \pm 4.53^{\mathrm{b}}$ & $24.95 \pm 5.64^{\mathrm{b}}$ & $31.13 \pm 4.39^{\mathrm{b}}$ \\
\hline
\end{tabular}

iDCs, immature dendritic cells; $\mathrm{H}, 50 \mu \mathrm{M}$ hesperetin. Data are presented as the means $\pm \mathrm{SEM} .{ }^{\mathrm{a}} \mathrm{p}<0.05 \mathrm{vs}$. iDCs + medium; ${ }^{\mathrm{b}} \mathrm{p}<0.05 \mathrm{vs}$. iDCs + Der $\mathrm{p} 1$.

A

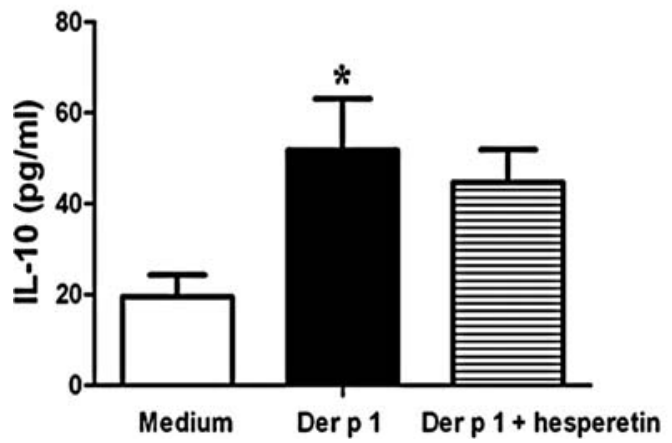

$\mathbf{B}$

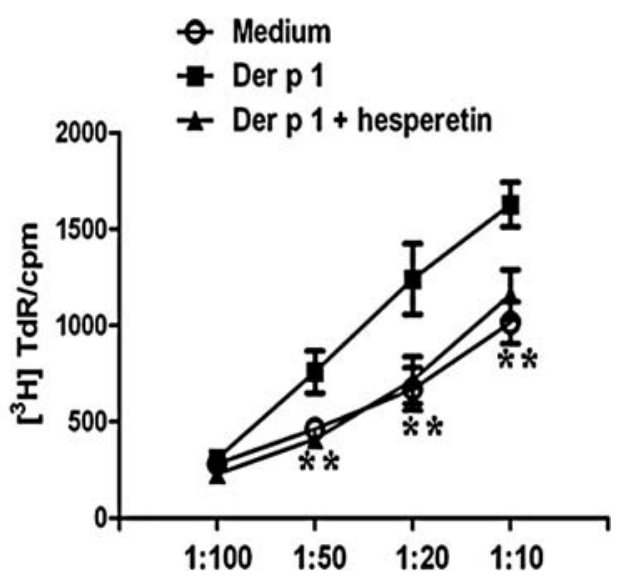

Figure 2. Hesperetin does not influence IL-10 production in Der p 1-stimulated Dendritic cells (DCs) but impairs their ability to induce T cell proliferation. (A) Immature DCs (iDCs) were cultured with medium alone or with Der p $1(100 \mathrm{ng} / \mathrm{ml})$ in the presence or absence of hesperetin $(50 \mu \mathrm{M})$ for $24 \mathrm{~h}$. Supernatants were collected and analysed for IL-10 by ELISA. (B) Autologous CD4 $4^{+} \mathrm{T}$ cells were cocultured at varying ratios with iDCs pulsed with medium alone or with Der $\mathrm{p} 1$ $(100 \mathrm{ng} / \mathrm{ml})$ in the presence or absence of hesperetin. After $96 \mathrm{~h}$ of culture, proliferation was assessed by means of the incorporation of ${ }^{3} \mathrm{H}$-thymidine. Data are expressed as means \pm SEM of ten independent experiments. ${ }^{*} \mathrm{p}<0.05$ in comparison with medium-pulsed DCs; ${ }^{* *} \mathrm{p}<0.05$ in comparison with Der $\mathrm{p} 1$-pulsed DCs.

\section{Results}

Hesperetin inhibits the phenotypic maturation of monocytederived dendritic cells. After 7 days of culture with GM-CSF and IL-4, monocytes differentiated into large round and nonadherent cells exhibiting protruding veils or dendrites typical of DCs. Generated cells were analyzed for the expression of the monocyte marker CD14 and the DC markers CD1a, HLADR, CD80, CD86 and CD83. The results show that these cells decreased the expression of CD14 and elevated the expression of CD1a, whereas HLA-DR, CD80, CD86 and CD83 were expressed at low levels (data not shown). This profile is specific for iDCs. In some experiments, we attempted to determine whether hesperetin influences the phenotypic maturation of DCs. We first evaluated the effect of hesperetin on the viability of DCs using the MTT assay. As depicted in Fig. 1, even at $50 \mu \mathrm{M}$ hesperetin had little cytotoxicity when incubated with cells for $24 \mathrm{~h}$. Therefore, all further experiments were performed using $50 \mu \mathrm{M}$ hesperetin.

As shown in Table I, pulsing with Der p 1 induced the increased expression of CD86, HLA-DR and CD83 (all $\mathrm{P}<0.05)$ but not CD80 $(\mathrm{P}>0.05)$ in DCs. Treatment with hesperetin significantly inhibited the Der $\mathrm{p} 1$-induced expression of CD86, HLA-DR and CD83 (all P<0.05) in DCs.
Hesperetin does not influence IL-10 production in Der $p$ 1stimulated dendritic cells but impairs their ability to induce $T$ cell proliferation. As IL-12 and -10 are known to play key roles in the modulation of $\mathrm{T}$ cell response, their production by DCs was evaluated. When iDCs from asthmatic patients sensitive to the house dust mite were incubated with Der $\mathrm{p} \mathrm{1,}$ a significant production of IL-10 were observed (Fig. 2A), whereas IL-12 was not detected in any of the culture supernatants from the DCs tested (data not shown). Notably, hesperetin did not impair the production of IL-10 (Fig. 2A).

To test whether hesperetin inhibits the accessory function of Der $\mathrm{p}$ 1-stimulated DCs on T cell proliferation, DCs from 8 -day cultures that had been incubated with or without hesperetin for $24 \mathrm{~h}$ were tested for their capacity to stimulate autologous T cells. As expected, iDCs markedly promoted T cell proliferation in response to Der $\mathrm{p} 1(\mathrm{P}<0.05$ for all $\mathrm{DC} / \mathrm{T}$ cell ratios, with the exception of the DC/T cell ratio of 1:100). However, hesperetin impaired the capacity of Der p 1-pulsed DCs to stimulate $\mathrm{T}$ cell proliferation $(\mathrm{P}<0.05$ for all $\mathrm{DC} / \mathrm{T}$ cell ratios, with the exception of the $\mathrm{DC} / \mathrm{T}$ cell ratio of $1: 100$ ) (Fig. 2B).

Hesperetin inhibits the capacity of Der p 1-pulsed dendritic cells to induce Th2 responses. To further clarify the effect of 

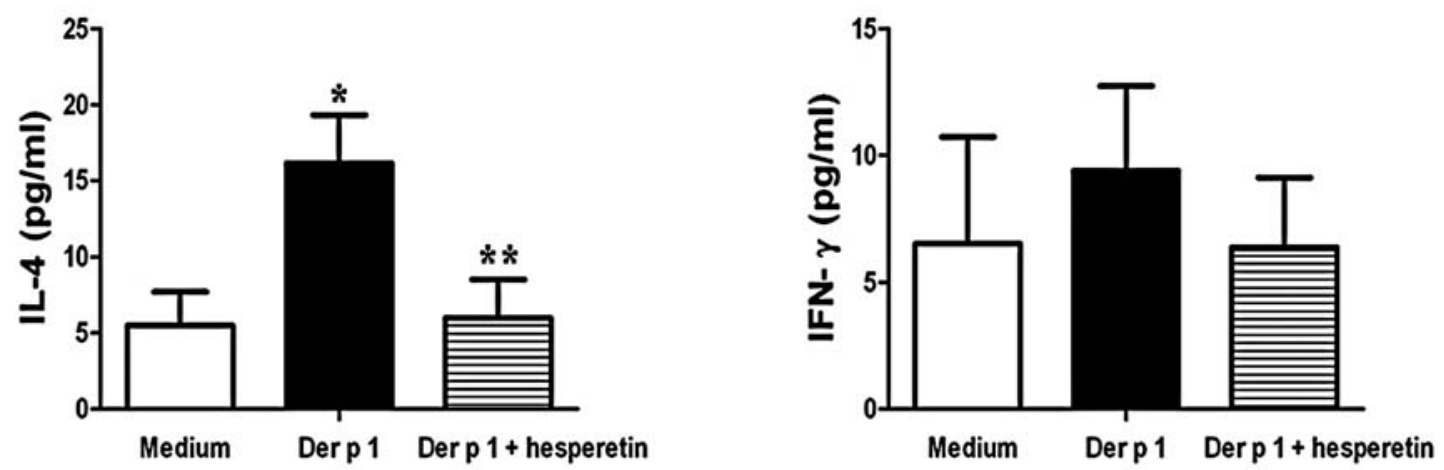

Figure 3. Hesperetin suppresses the capacity of Der p 1-pulsed dendritic cells (DCs) to induce Th2 polarization. CD4+ $\mathrm{T}$ cells were coincubated with various treated DCs at a ratio of 1:10 for $48 \mathrm{~h}$. Supernatants were harvested and assayed for IL-4 (A) and IFN- $\gamma$ (B) production by ELISA. Data are expressed as the means \pm SEM of ten independent experiments. "p $<0.05$ in comparison with medium-pulsed DCs; ${ }^{* *}$ p 0.05 in comparison with Der p 1-pulsed DCs.

hesperetin-treated DCs on Th1/Th2 balance, we measured IL-4 and IFN- $\gamma$ in the supernatants of the cultures. Naive autologous T cells primed with Der $\mathrm{p}$ 1-pulsed DCs differentiated into Th2 lymphocytes because they secreted pronounced amounts of IL-4 and low levels of IFN- $\gamma$ compared to samples of nonstimulated DCs (Fig. 3A and B). In contrast, T lymphocytes primed with DCs matured in the presence of hesperetin displayed a reduced production of IL-4.

Hesperetin suppresses the Der $p$ 1-induced nuclear translocation of $N F-\kappa B$ p65 in dendritic cells. Normally, NF- $\kappa \mathrm{B}$ is present in the cytoplasm in an inactive state and bound to a member of the IкB inhibitor protein family. Following stimulation, IкB $\alpha$ is phosphorylated and degraded. Subsequently, unbound NF- $\mathrm{KB}$ translocates to the nucleus and transactivates various downstream genes. Since the activation of $\mathrm{NF}-\kappa \mathrm{B}$ is an important event in DC maturation (18), and Der p 1 has been shown to promote the nuclear translocation of $\mathrm{NF}-\kappa \mathrm{B}$ p65 in asthmatic bronchial epithelial cells (19), we explored whether hesperetin affects the Der $\mathrm{p}$ 1-induced activation of $\mathrm{NF}-\kappa \mathrm{B}$ in DCs. Hesperetin pretreated DCs were exposed to $100 \mathrm{ng} / \mathrm{ml} \mathrm{Der} \mathrm{p} 1$ for $60 \mathrm{~min}$. The results revealed that the increased phosphorylation of I $\mathrm{B} \alpha$ with the nuclear translocation of NF-кBp65 in Der p 1-pulsed DCs was blocked by hesperetin (Fig. 4). These data indicate that hesperetin might inhibit the translocation of NF- $\mathrm{BB}$ by disturbing $\mathrm{I} \kappa \mathrm{B} \alpha$ degradation.

\section{Discussion}

DCs play a central role in the initiation and maintenance of immune response (2). Our experimental system used DCs and autologous lymphocytes from patients with allergic asthma, in which allergen stimulation induces a Th2 response (20). Hesperetin is known to possess anti-inflammatory (9) and anti-allergic activity $(12,13)$. The present study evaluated the effects of hesperetin on the expression of surface molecules, cytokine production and T-cell differentiation, as well as the signaling pathway underlying these phenomena in monocytederived DCs. The maturation and function of DCs was not inhibited by reduced DC viability, because hesperetin $(50 \mu \mathrm{M})$ was not toxic to DCs.

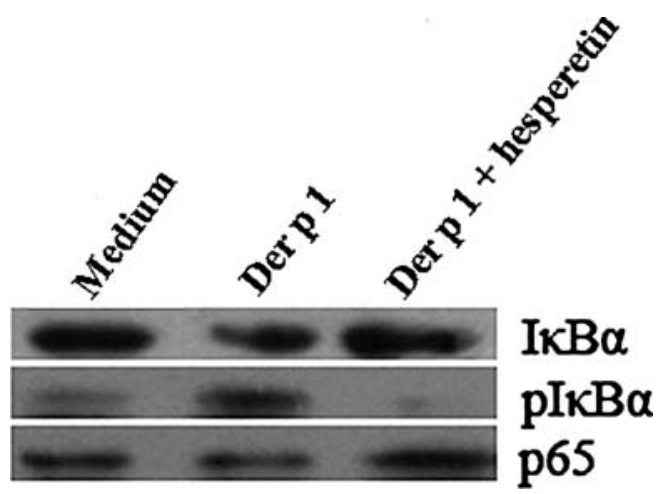

Figure 4. Inhibitory effects of hesperetin on Der p 1-induced IкB $\alpha$ phosphorylation and the nuclear translocation of NF- $\kappa \mathrm{B}$ in dendritic cells. Western blot analysis was performed to detect IкB $\alpha, \mathrm{pI \kappa \textrm {B }} \alpha$ and $\mathrm{p} 65$ levels in cytoplasmic extracts ( $80 \mu \mathrm{g}$ protein) from each group. The results represent six separate experiments that yielded similar results.

By controlling the strength and duration of TCR triggering, the pattern of costimulatory molecule expression and the production of polarizing cytokines, DCs determine the outcome of the primary $\mathrm{T}$ cell response of tolerance, unpolarized Th0, or polarized Th1 or Th2 (21). In this study, we demonstrated that treatment with hesperetin inhibited the Der $\mathrm{p} 1$-induced expression of HLA-DR, CD86 and CD83 in DCs. These results suggest that hesperetin may inhibit the phenotypic maturation of DCs. A significant increase in IL-10 but not IL-12 production was also obesrved in DCs matured in response to Der $\mathrm{p} 1$. However, hesperetin did not impair the production of IL-10. Overall, hesperetin has a major influence on the signals involved in $\mathrm{T}$ cell activation.

Changes in surface marker expression and cytokine production were also reflected at a functional level when the allostimulatory capacity of DCs in a mixed lymphocyte reaction was analyzed, and naive autologous T cells primed with Der $\mathrm{p}$ 1-pulsed DCs from allergic asthma patients differentiated into Th2 lymphocytes. This last is in line with a report by Hammad et al (20). Hesperetin potently inhibited the capacity of mature DCs to stimulate the proliferation of $\mathrm{CD}^{+} \mathrm{T}$ cells, accompanied by a reduction in the production of IL-4. These data indicated that hesperetin inhibited the Th2 polarization induced 
by Der p 1-pulsed DCs, and that this inhibition might depend on the down-regulation of HLA-DR, CD86 expression in DCs. As NF- $\mathrm{KB}$ activation controls both the expression of costimulatory molecules and the major histocompatibility complex in DCs (22), we conducted an evaluation of NF- $\mathrm{KB}$ activation to characterize the mechanism underlying the ability of hesperetin to inhibit DCs maturation. Der p 1-pulsed DCs clearly exhibited the increased degradation of $\mathrm{I} \kappa \mathrm{B} \alpha$ and the nuclear translocation of NF- $\mathrm{B}$ p65. However, hesperetin virtually reduced the nuclear translocation of NF- $\mathrm{\kappa B}$ p65 by blocking IкB $\alpha$ degradation (23).

IL-12, a DC-derived cytokine, has multiple immunoregulatory functions that activate the Th1 subset. The Th2 cytokine IL-10 plays an essential role in immune tolerance to allergens. A notable observation in this study was that hesperetin did not affect IL-10 levels in DCs. This may have to do with the fact that IL-10 is regulated by STAT3, and not by $\mathrm{NF}-\kappa \mathrm{B}(17,24)$. We have not been able to evaluate the effect of hesperetin on IL-12 production by $\mathrm{mDCs}$, as IL-12 was not detected in any of the culture supernatants. Previous evidence suggests that NF- $\mathrm{KB}$ controls cytokine production, such as that of IL-12, by means of DCs (22). We propose that hesperetin might also regulate IL-12 production. However, future studies examining this hypothesis are requuired.

In conclusion, $N F-\kappa B$ is a critical transcription factor involved in the pathogenesis of many disorders, including inflammatory diseases such as asthma. Inhibition of NF- $\mathrm{KB}$ accordingly results in a reduced capacity of DCs to secrete proinflammatory cytokines and to stimulate naive $\mathrm{CD}^{+} \mathrm{T}$ cells. Thus, developing and identifying specific components that modulate NF- $\mathrm{KB}$ without adverse side-effects would be beneficial. The current study shows that hesperetin inhibits the maturation and function of DCs from patients with allergic asthma by suppressing the activation of NF-кB. This implies that hesperetin is a candidate therapeutic agent for allergies and inflammation.

\section{Acknowledgements}

We are grateful to all the subjects who participated in the study. This work was supported by grants from the National Natural Science Foundation of China (30400191 and 30570797 to L.F.Z. and K.S.Y.), the Jiangsu Key Subject of Medicine (XK200713 to K.S.Y.), the Summit Project of Jiangsu Personnel (06B035 to L.F.Z.) and the Jiangsu Key Principal Investigator of Medicine (RC2007043 to L.F.Z.).

\section{References}

1. Hammad H, Kool M, Soullié T, Narumiya S, Trottein F, Hoogsteden $\mathrm{HC}$ and Lambrecht BN: Activation of the $\mathrm{D}$ prostanoid 1 receptor suppresses asthma by modulation of lung dendritic cell function and induction of regulatory T cells. J Exp Med 204: 357-367, 2007.

2. Banchereau J and Steinman RM: Dendritic cells and the control of immunity. Nature 392: 245-252, 1998.

3. Bratke K, Lommatzsch M, Julius P, Kuepper M, Kleine HD, Luttmann W and Virchow JC: Dendritic cell subsets in human bronchoalveolar lavage fluid after segmental allergen challenge. Thorax 62: 168-175, 2007.

4. Vermaelen $\mathrm{K}$ and Pauwels R: Pulmonary dendritic cells. Am J Respir Crit Care Med 172: 530-551, 2005.
5. van Rijt LS, Jung S, KleinJan A, Vos N, Willart M, Duez C, Hoogsteden $\mathrm{HC}$ and Lambrecht $\mathrm{BN}$ : In vivo depletion of lung $\mathrm{CD} 11 \mathrm{c}^{+}$dendritic cells during allergen challenge abrogates the characteristic features of asthma. J Exp Med 201: 981-991, 2005.

6. Matsue H, Yang C, Matsue K, Edelbaum D, Mummert M and Takashima A: Contrasting impacts of immunosuppressive agents (rapamycin, FK506, cyclosporin A and dexamethasone) on bidirectional dendritic cell-T Cell interaction during antigen presentation. J Immunol 169: 3555-3564, 2002.

7. Bielory L: Complementary and alternative interventions in asthma, allergy and immunology. Ann Allergy Asthma Immunol 93 (Suppl 1): S45-S54, 2004.

8. Cai Y, Luo Q, Sun M and Corke H: Antioxidant activity and phenolic compounds of 112 traditional Chinese medicinal plants associated with anticancer. Life Sci 74: 2157-2184, 2004.

9. Galati EM, Monforte MT, Kirjavainen S, Forestieri AM, Trovato A and Tripodo MM: Biological effects of hesperidin, a citrus flavonoid. (Note I): antiinflammatory and analgesic activity. Farmaco 40: 709-712, 1994.

10. Cooray HC, Janvilisri T, van Veen HW, Hladky SB and Barrand MA: Interaction of the breast cancer resistance protein with plant polyphenols. Biochem Biophys Res Commun 317: 269-275, 2004

11. O'Prey J, Brown J, Fleming $\mathrm{J}$ and Harrison PR: Effects of dietary flavonoids on major signal transduction pathways in human epithelial and hepatic cells. Biochem Pharmacol 66: 2075-2088, 2003.

12. Lee NK, Choi SH, Park SH, Park EK and Kim DH: Antiallergic activity of hesperidin is activated by intestinal microflora. Pharmacology 71: 174-180, 2004.

13. Kobayashi S and Tanabe S: Evaluation of the anti-allergic activity of Citrus unshiu using rat basophilic leukemia RBL$2 \mathrm{H} 3$ cells as well as basophils of patients with seasonal allergic rhinitis to pollen. Int J Mol Med 17: 511-515, 2006.

14. Bateman ED, Hurd SS, Barnes PJ, Bousquet J, Drazen JM, Fitzgerald M, Gibson P, Ohta K, O'Byrne P, Pedersen SE, Pizzichini E, Sullivan SD, Wenzel SE and Zar HJ: Global strategy for asthma management and prevention: GINA executive summary. Eur Respir J 31: 143-178, 2008.

15. Zhou LF, Zhang MS, Yin KS, Ji Y, Xie WP, Cui XF and Ji XH: Effects of adenoviral gene transfer of mutated ІкB $\alpha$, a novel inhibitor of NF- $\mathrm{KB}$, on human monocyte-derived dendritic cells. Acta Pharmacol Sin 27: 609-616, 2006.

16. Lee S, Lee M and Kim SH: Eupatilin inhibits $\mathrm{H}(2) \mathrm{O}(2)$-induced apoptotic cell death through inhibition of mitogen-activated protein kinases and nuclear factor- $\mathrm{\kappa B}$. Food Chem Toxicol 46: 2865-2870, 2008.

17. Zhou LF, Zhang MS, Hu AH, Zhu Z and Yin KS: Selective blockade of NF- $\kappa$ B by novel mutated I $\mathrm{BB} \alpha$ suppresses CD3/ CD28-induced activation of memory $\mathrm{CD}^{+} \mathrm{T}$ cells in asthma. Allergy 63: 509-517, 2008.

18. Vakkila J, Demarco RA and Lotze MT: Coordinate NF-кB and STAT1 activation promotes development of myeloid type 1 dendritic cells. Scand J Immunol 67: 260-269, 2008.

19. Stacey MA, Sun G, Vassalli G, Marini M, Bellini A and Mattoli S: The allergen Der p1 induces NF-kappaB activation through interference with IkappaB alpha function in asthmatic bronchial epithelial cells. Biochem Biophys Res Commun 236: 522-526, 1997.

20. Hammad H, Charbonnier AS, Duez C, Jacquet A, Stewart GA, Tonnel AB and Pestel J: Th2 polarization by Der $\mathrm{p}$ 1-pulsed monocytederived dendritic cells is due to the allergic status of the donors. Blood 98: 1135-1141, 2001.

21. Lambrecht BN, Peleman RA, Bullock GR and Pauwels RA: Sensitization to inhaled antigen by intratracheal instillation of dendritic cells. Clin Exp Allergy 30: 214-224, 2000.

22. Verma IM: Nuclear factor (NF)- $\mathrm{kB}$ proteins: therapeutic targets. Ann Rheum Dis 63: ii57-ii61, 2004.

23. Kim JY, Jung KJ, Choi JS and Chung HY: Modulation of the age-related nuclear factor- $\mathrm{KB}(\mathrm{NF}-\kappa \mathrm{B})$ pathway by hesperetin. Aging Cell 5: 401-411, 2006.

24. Van Scott MR, Justice JP, Bradfield JF, Enright E, Sigounas A and Sur S: IL-10 reduces Th2 cytokine production and eosinophilia but augments airway reactivity in allergic mice. Am J Physiol Lung Cell Mol Physiol 278: 667-674, 2000. 